CHAPTER 27

\title{
Animals in a Wider Context
}

\author{
Nick J. Overton and Ben Elliott
}

\section{Introduction}

The extensive assemblage of faunal remains preserved at Star Carr affords an excellent opportunity to explore the lifeways of the humans that lived in the local landscape: it indicates which species were hunted, how humans broke down animal bodies, how they moved parts across sites and landscapes and how they were deposited. It also offers a unique window into the techniques, processes and forms of the osseous technology that clearly made up a substantial element of the Early Mesolithic toolkit. However, this material and data not only reveals details of life at Star Carr; by comparing it to the other very Early Mesolithic assemblages in Britain and Europe, Star Carr can be placed within its wider context. How similar were lives across Early Mesolithic North-West Europe? Were humans engaged in the same practices across this area, or were their lives shaped by specific characteristics of their local environments? And if so, does a comparison of the Star Carr assemblage with the wider evidence highlight any particular affinities or differences between North-West European Early Mesolithic groups? In order to compare hunting practices and lifeways across North-West European sites, the frequencies of the five main ungulate species, namely aurochs, elk, red deer, roe deer and wild boar have been collated (see Table 27.1). These species have been selected as the quantification data for these species is readily available, and they are regularly recovered in good numbers, in part due to their size and robusticity. This is not to present an account that ignores the potentially significant role other resources, such as birds, smaller mammals and fish may have played in the Early Mesolithic diet; however, due to their small size, and associated problems with preservation and recovery, the remains of these species are much more infrequent and therefore not suitable for inter-site comparisons.

\section{Faunal assemblage}

\section{Star Carr in the British context}

Within the British context, the Star Carr assemblage stands out as by far the largest, in terms of the number of identified specimens (see Table 27.1) and the minimum number of individuals of each species, with all species except wild boar being represented by double Figures (Chapter 23). In contrast, the only other sites with any

How to cite this book chapter:

Overton, N. J. and Elliott, B. 2018. Animals in a Wider Context. In: Milner, N., Conneller, C. and Taylor, B. (eds.) Star Carr Volume 2: Studies in Technology, Subsistence and Environment, pp. 335-343. York: White Rose University Press. DOI: https://doi.org/10.22599/book2.m. Licence: CC BY-NC 4.0 


\begin{tabular}{|c|c|c|c|c|c|c|c|c|c|c|c|}
\hline & \multicolumn{2}{|c|}{ Aurochs } & \multirow{2}{*}{\begin{tabular}{|c|} 
Elk \\
NISP \\
\end{tabular}} & \multirow[b]{2}{*}{$\%$} & \multicolumn{2}{|c|}{ Red deer } & \multicolumn{2}{|c|}{ Roe deer } & \multicolumn{2}{|c|}{ Wild boar } & \multirow[t]{2}{*}{ NISP Total } \\
\hline & NISP & $\%$ & & & NISP & $\%$ & NISP & $\%$ & NISP & $\%$ & \\
\hline Star Carr & 315 & 17.47 & 275 & 15.25 & 995 & 55.19 & 175 & 9.71 & 4 & 2.38 & 1803 \\
\hline \multicolumn{12}{|l|}{ Britain } \\
\hline Seamer C & 22 & 64.71 & 2 & 5.88 & 8 & 23.53 & 2 & 5.88 & 0 & 0 & 34 \\
\hline $\begin{array}{l}\text { Flixton School } \\
\text { House Farm }\end{array}$ & 17 & 100 & 0 & 0 & 0 & 0 & 0 & 0 & 0 & 0 & 17 \\
\hline Thatcham III & 7 & 2.92 & 2 & 0.83 & 86 & 35.98 & 38 & 15.89 & 106 & 44.35 & 239 \\
\hline Faraday Road & 16 & 2.18 & 0 & 0 & 56 & 7.62 & 26 & 3.54 & 637 & 86.67 & 735 \\
\hline Three Ways Wharf & 0 & 0 & 0 & 0 & 671 & 81.43 & 153 & 18.56 & 0 & 0 & 824 \\
\hline $\begin{array}{l}\text { Former Sanderson } \\
\text { Site }^{\star}\end{array}$ & 0 & 0 & 0 & 0 & 170 & 55.92 & 0 & 0 & 134 & 44.08 & 304 \\
\hline \multicolumn{12}{|l|}{ France } \\
\hline Warluis IIIb & 6 & 7.80 & 0 & 0 & 54 & 70.13 & 12 & 15.58 & 5 & 6.49 & 77 \\
\hline \multicolumn{12}{|l|}{ The Netherlands } \\
\hline $\begin{array}{l}\text { Zutphen- } \\
\text { Ooijerhoek } \\
\text { (site M) }\end{array}$ & 0 & 0 & 0 & 0 & 7 & 35 & 5 & 25 & 8 & 40 & 20 \\
\hline \multicolumn{12}{|l|}{ Germany } \\
\hline $\begin{array}{l}\text { Friesack } \\
\text { 4-complex I }\end{array}$ & 16 & 2.55 & 57 & 9.09 & 221 & 35.25 & 242 & 38.60 & 91 & 14.51 & 627 \\
\hline $\begin{array}{l}\text { Friesack } \\
\text { 4-complex II }\end{array}$ & 4 & 0.39 & 53 & 5.23 & 340 & 33.53 & 424 & 41.81 & 193 & 19.03 & 1014 \\
\hline Friesack 27 sk 1 & 10 & 7.75 & 23 & 17.83 & 49 & 37.98 & 38 & 29.46 & 9 & 6.98 & 129 \\
\hline Potsdam Schlaatz ${ }^{\star *}$ & 44 & 95.65 & & 0 & 1 & 2.17 & & 0 & 1 & 2.17 & 46 \\
\hline $\begin{array}{l}\text { Bedburg- } \\
\text { Königshoven }\end{array}$ & 362 & 80.27 & 0 & 0 & 34 & 7.54 & 49 & 10.86 & 6 & 1.33 & 451 \\
\hline $\begin{array}{l}\text { Mönchengladbach- } \\
\text { Geneicken }\end{array}$ & $\mathrm{n} / \mathrm{a}$ & 100 & & & & & & & & & $\mathrm{n} / \mathrm{a}$ \\
\hline \multicolumn{12}{|l|}{$\begin{array}{l}\text { Southern } \\
\text { Scandinavia }\end{array}$} \\
\hline Lundby LM1 & & & 97 & 100 & & & & & & & 97 \\
\hline Lundby LM2 & & & 729 & 100 & & & & & & & 729 \\
\hline Lundby LM3 & & & 515 & 100 & & & & & & & 515 \\
\hline Lundby LM4 & & & 127 & 100 & & & & & & & 127 \\
\hline Lundby LM5 $5^{\star * *}$ & Pres. & & & Dom. & Pres. & & Pres. & & Pres. & & $\mathrm{n} / \mathrm{a}$ \\
\hline Skottemarke & & & $\mathrm{n} / \mathrm{a}$ & 100 & & & & & & & $\mathrm{n} / \mathrm{a}$ \\
\hline Favrbo & & & $\mathrm{n} / \mathrm{a}$ & 100 & & & & & & & $\mathrm{n} / \mathrm{a}$ \\
\hline Vig & $\mathrm{n} / \mathrm{a}$ & 100 & & & & & & & & & $\mathrm{n} / \mathrm{a}$ \\
\hline
\end{tabular}

Table 27.1: Species frequency of red deer, roe deer, aurochs, elk and wild boar at North-West European Early Mesolithic sites, based on number of identified specimen (NISP) data. Seamer C (Uchiyama et al. forthcoming), Flixton School House Farm (Overton and Taylor forthcoming), Thatcham III (Overton 2014), Faraday Road (Overton 2014), Three Ways Wharf (Overton 2014), Former Sanderson Site (Overton 2014), Warluis IIIb (Coutard et al. 2010), Zutphen-Ooijerhoek site M (Bos et al. 2005), Friesack 4-complex I (Schmölcke 2016), Friesack 4-complex II (Schmölcke 2016), Friesack 27 sk 1 (Groß 2014), Potsdam Schlaatz ${ }^{\star *}$ (Gramsch 1987a; 1987b; Gustavs 1987), Bedburg-Königshoven (Street 1993), Mönchengladbach-Geneicken (Heinen 2014), Lundby LM1 (Leduc 2014), Lundby LM2 (Leduc 2014), Lundby LM3 (Leduc 2014), Lundby LM4 (Pedersen and Brinch Petersen in press), Lundby LM5 (Leduc 2014), Skottemarke (Pedersen and Brinch Petersen in press), Favrbo (Pedersen and Brinch Petersen in press), Vig (Noe-Nygaard 1973). For date ranges of European sites, see Chapter 12; for British sites, see Conneller et al. (2016). ${ }^{\star}$ NISP over inflates red deer (MNI Figures indicate wild boar more frequent). ${ }^{* *}$ NISP counts for Potsdam Schlaatz calculated from illustrations in Gustavs (1987). ${ }^{* * *}$ Dom. indicates dominant. Pres. indicates present in assemblage. 
species represented by more than 10 individuals are Three Ways Wharf and Faraday Road, and in both cases, it is only the dominant species that are this frequent (cf. Overton 2014). The closest potential parallel to Star Carr in terms of size could be Thatcham, in the Kennet Valley; however, this assemblage originates from five separate 'sites' (trenches), and only some of the material is still in existence (see Chapter 11). As a result, only the assemblage from Thatcham III is deemed suitable for comparison and, as such, is much smaller than originally reported (cf. Wymer 1962). Therefore, the Star Carr assemblage offers a picture of Early Mesolithic hunting activity at a scale unlike any other site in Britain.

The presence and frequency of species highlights a clear difference between the sites in the Vale of Pickering, including Star Carr, and those in Southern Britain. At the northern sites, assemblages are dominated by the largest species, namely red deer, aurochs and elk; however, at the southern sites, whilst red deer remains prominent, both elk and aurochs are either extremely infrequent or entirely absent. It should be noted that elk and aurochs are also recorded at further southern sites, at Broxbourne, Eton Rowing Course and Wawcott XXX (Froom 2012; Allen et al. 2013; Chapter 11). However, whilst these indicate populations of these species were present within Southern Britain during the Early Mesolithic, they are clearly not represented in the quantity that we see within the assemblages of Star Carr and other northern sites. In stark contrast to this, the frequency of wild boar indicate the inverse pattern, being dominant on a number of southern sites, yet either very infrequent, such as at Star Carr, or absent within northern assemblages. If a single, homogenous mammal population inhabited Britain, it could be argued that the much larger size of the Star Carr assemblage presents a greater chance of including higher frequencies of a wider range of species. However, whilst that could explain the higher frequencies of elk and aurochs at Star Carr, it does not explain why wild boar are so infrequent. Furthermore, the other northern sites, which also present higher elk and aurochs frequencies, are much smaller, suggesting this pattern is not a function of assemblage size. Instead, the species frequency difference presented here suggest a clear difference in the species hunted at the broadly contemporary sites in the Star Carr environ, and in Southern Britain (Chapter 11).

The disparity in species frequencies is best explained as the result of environmental changes, in which denser forest and understorey vegetation colonised Southern Britain earlier, and pushed the majority of the open forest adapted elk and aurochs populations northwards (Overton forthcoming). However, this is not to say that human choice did not also play a role in shaping these patterns; rarer species may not have been regularly hunted, not only because of infrequent hunter-prey encounters, but also because humans chose not to, either out of a practical desire not to form a reliance on scarce species, or out of broader ontological understandings of rare species as distinctive or different (cf Overton 2016). Whether purely environmental, or mediated by human choice, this pattern highlights the fact that Mesolithic groups across Britain hunted different species. In turn, this would have significantly impacted their lifeways, shaping specific hunting techniques, affecting technology use, requiring movement through particular environments, at different times in the day, and across the year. Therefore, whilst Star Carr is the largest assemblage in Britain, it is not necessarily the most representative of Early Mesolithic life in Britain; indeed, differences in fauna and hunting practices between Northern and Southern Britain suggest no single site could offer a suitable picture for the whole of Britain. Instead, Star Carr is significant in providing us with an unparalleled picture of the lives and lifeways of the earliest Mesolithic hunter-gatherers in Northern Britain, whose hunting focused on the largest ungulate species.

Beyond the size of assemblage, the Star Carr material also indicates a wide hunting breadth (see Table 27.1), which is not evident to the same extent at a number of other British sites. The closest parallel from the southern sites would be Thatcham III, which evidences the hunting of all five main species, with relatively high levels of red deer, wild boar and, to a slightly lesser extent, roe deer. In contrast, sites such as Faraday Road and Three Ways Wharf demonstrate a much clearer focus on a single species (see Table 27.1). However, species breadth is likely to be shaped by the temporal span of a site; both Star Carr and Thatcham are palimpsests, made up of material derived from multiple occupations, in which different species were hunted in a series of hunting events. Conversely, sites such as Three Ways Wharf are potentially the result of a single occupation, and therefore reflect the specific nature of that single event. Although a number of the southern sites represent more temporally discrete events, taken as a whole, they indicate that, like Star Carr, a range of species were being hunted within the landscape (Chapter 11). This indicates a more broadly shared approach to hunting across the British Early Mesolithic, which is manifest within each assemblage in locally specific ways, based on the nature and length of occupation, and the broader environmental characteristics. However, whilst hunting a range of species does not highlight Star Carr as different to wider British practices, the sheer size of the assemblage, 
the number of individuals within it and the overall intensity and scale of occupation does makes it distinctive within the British context.

\section{Star Carr in the wider European context}

Within the wider context of North-West Europe, Star Carr remains notable as the largest faunal assemblage (see Table 27.1), although the Early Mesolithic assemblages from Friesack 4 and 27 together contain a very similar amount of identified specimens. These are recovered from both temporally and spatially disparate sites, which present problems in trying to view them as a single amalgamated assemblage (Chapter 12).

\section{Species presence and frequency}

The presence and frequency of species across North-West European sites present a number of patterns which allow an exploration of both Star Carr and Britain within the wider European context (see Figure 27.1). Firstly, the high frequencies of red deer, roe deer and wild boar in Southern Britain is echoed in the more southerly and westerly European sites, such as Warluis IIIb in the Paris Basin (Coutard et al. 2010) and Zutphen-Ooijerhoek site $\mathrm{M}$ in eastern Netherlands (Bos et al. 2005). Across these sites, aurochs are equally infrequent or absent; however, they become more frequent moving eastwards and northwards into Germany and Denmark, with a particular dominance at Bedburg-Königshoven and Mönchengladbach-Geneicken in Western Germany (Street 1993; Heinen 2014). The most restricted range is exhibited by elk, which are only present at Friesack 4 and 27 in Northern Germany, and at Lundby, Skottemarke and Favrbo in Denmark (Groß 2014; Leduc 2014; Schmölcke 2016; Pedersen and Brinch Petersen in press). This pattern broadly reflects the species distributions within Britain, with the largest species more restricted to northerly areas, in particular elk, echoing previous suggestions that elk are a frequent and even dominant species within Scandinavian and Baltic Mesolithic assemblages (Bridault 1992).

These varying frequencies of species suggest a number of similarities and differences can be drawn between Star Carr and these other European sites. Firstly, the lack of aurochs and elk in France and the Netherlands may suggest lifeways in these areas were notably different to those at Star Carr, with hunting practices focusing on the more gregarious wild boar and red deer, and the small and secretive roe deer. In contrast, the more northerly sites in Germany and Denmark which show the presence of both aurochs and elk indicate hunting patterns that were more similar to those at Star Carr. The hunting of elk at Early Mesolithic Danish sites has previously been argued as being a significant act that was tightly bound into cultural aspects of life (Leduc 2014); it is interesting to consider the ways in which groups regularly hunting similar species, such as groups at Star Carr, Friesack, Bedburg-Königshoven and sites in Denmark, may have shared similar aspects of daily life as a result.

However, although these northern sites are tied together by the presence of elk and aurochs, they are not entirely comparable. In contrast to the broad range of species hunted at Star Carr, the Danish sites present a much narrower species range, heavily focused on elk, a pattern which supports previous suggestions that they represent the preferred game (Leduc 2014). This pattern may, in part, be the result of the clear difference between the Star Carr assemblage, being a palimpsest of repeated occupation, and the Danish sites, which are predominantly sites with a single phase of deposition, such as the discrete deposits of elk at Lundby 1-4, Skottemarke and Favrbo (Leduc 2014; Pedersen and Brinch Petersen in press). It is difficult to say whether larger, multi-phase faunal deposits in Denmark exist but have yet to be found, or the single discrete deposits mentioned here are characteristic of all Early Mesolithic activity in Denmark. However, the assemblage from Lundby 5 is reported as a more typical 'domestic' assemblage, with a mix of species, including red deer, roe deer, wild boar and aurochs (Pedersen and Brinch Petersen in press), and single bones of red deer, roe deer, wild boar and a possible elk from Flaadet (Møhl 1980) do at least suggest a wider hunting breadth than may initially be apparent. In the same vein, whilst the assemblages from Friesack 4 and 27 indicate a wide hunting breadth (Table 27.1), aurochs and elk are infrequent at Friesack 4 (complex I and II), and the assemblages overall are notable for the very high frequencies of roe deer, which provides a clear contrast to Star Carr. At Bedburg-Königshoven, the species ratio is heavily weighted to aurochs, and lacks elk altogether, which again contrasts the red deer, elk and aurochs dominated assemblage at Star Carr. 


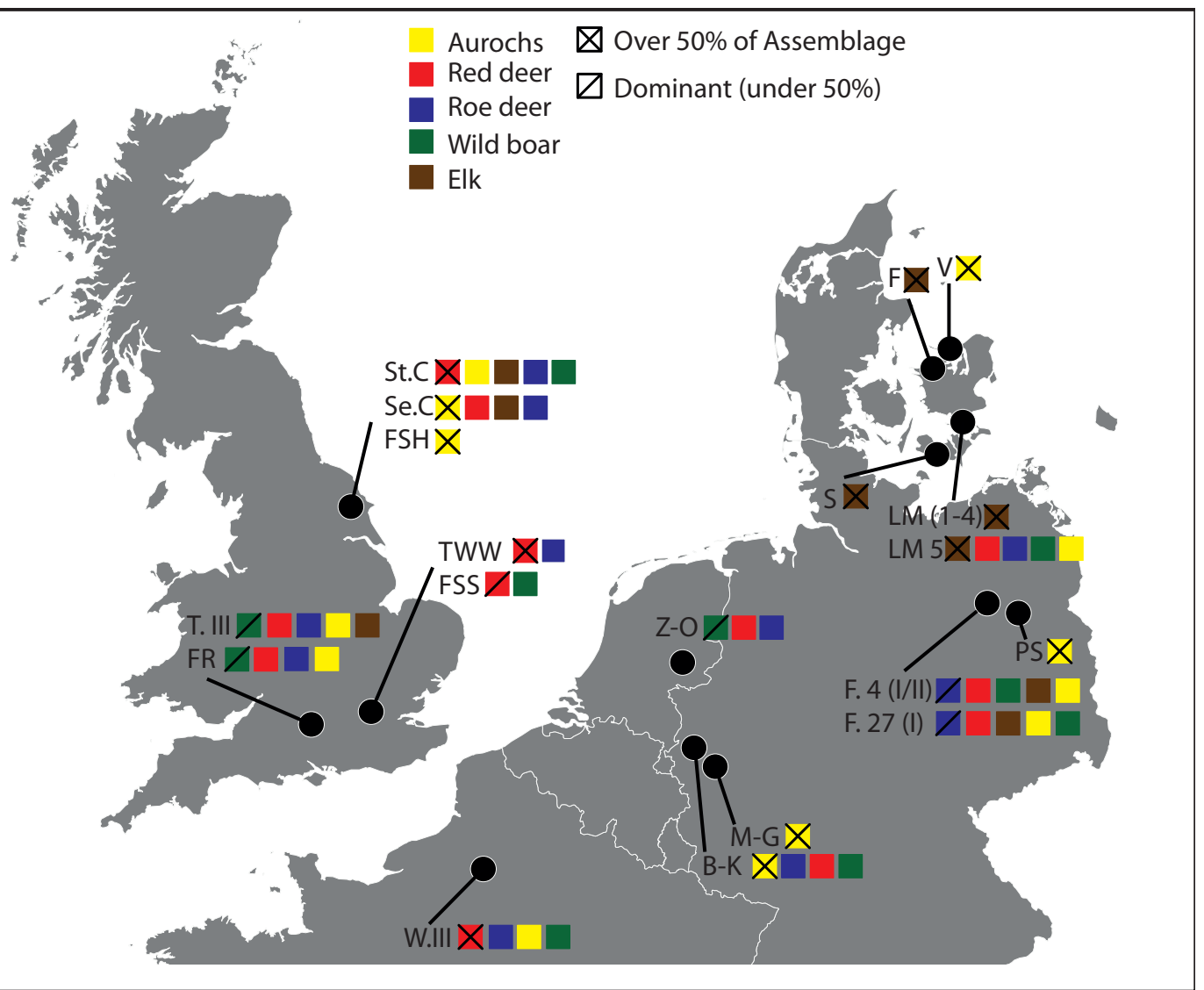

Figure 27.1: Presence and relative frequency of red deer, roe deer, aurochs, elk and wild boar in Early Mesolithic assemblages in North-West Europe. Order of species at each site indicates relative frequency, with most frequent on the left, and least frequent on the right. Based on the quantification of species by number of identified specimens (NISP) data, as presented in Table 27.1. Key: St.C: Star Carr. Se.C: Seamer Carr C. FSH: Flixton School House Farm. TWW: Three Ways Wharf. FSS: Former Sanderson Site. T.III: Thatcham III. FR: Faraday Road. W.III: Warluis IIIb. Z-O: Zutphen-Ooijerhoek site M. B-K: Bedburg-Königshoven M-G: Mönchengladbach-Geneicken. F.4 (I/II): Friesack 4 (complex I and II). F.27 (I): Friesack 27. PS: Potsdam Schlaatz. LM1-5: Lundby Mose 1-5. S: Skottemarke. F: Favrbo. V: Vig (Copyright Nick Overton, CC BY-NC 4.0).

Overall, whilst a number of the more northerly sites share a similar breadth of species as Star Carr, including elk and aurochs, they also exhibit more specific patterns. Star Carr, Friesack, Bedburg-Königshoven and possibly the sites in Denmark all existed within environments where elk, aurochs, red deer, roe deer and wild boar were present (except for elk at Bedburg-Königshoven). The faunal assemblages indicate the hunter-gatherers occupying these sites all engaged in hunting strategies that included all of these species; however, these manifested themselves in specific patterns, such as the dominance of roe deer at Friesack, or aurochs at Bedburg-Königshoven. Similarly, the sites in France and the Netherlands, whilst lacking the larger elk and aurochs, most probably due to changes in vegetation (cf. Overton forthcoming), also demonstrate hunting strategies that targeted a range of species. In this sense, all of the Early Mesolithic sites in Europe can be seen as adhering to a similar broad hunting strategy, in which humans predated on a broad range of ungulate species. However, this strategy manifests itself in specific ways in different areas and different sites, based on location, environment and local animal populations. It is important to remember that differences in species frequency within site assemblages may also be the result of hunting choices made by specific groups, but whether 
dominance of particular species is the result of choice or abundance, the practice of hunting specific species would become bound into the local and perhaps regional identities of Early Mesolithic hunter-gatherers. Therefore, whilst groups across North-West Europe may have adhered to broadly similar hunting strategies, the specific practices associated with hunting particular species may have led to clearer similarities between areas; as a result, the occupants of Star Carr may have shared more aspects of their life with the groups hunting larger ungulate species in Northern Germany and Denmark.

\section{Site use and deposition}

Comparison of North-West European Early Mesolithic sites clearly demonstrate a range of different tasks and activities taking place, with a number of sites representing just a single or very discrete period of activity. In Germany, the aurochs at Potsdam-Schlaatz was represented by the skull, spine and ribs, indicating an individual that was killed and butchered before the limbs scapula and pelvic girdle were removed (Gramsch 1987a; Gramsch 1987b; Gustavs 1987). At Mönchengladbach-Geneicken, close to Bedburg-Königshoven, the majority of a single aurochs was recovered, which was killed and processed for meat and marrow on site, before the split long bones were deposited back with the carcass (Heinen 2014). Similarly in Denmark, discrete depositions of elk have been recovered at Lundby Mose, Skottemarke and Favrbo, in each case containing the partial remains of one or multiple individuals (Leduc 2014; Pedersen and Brinch Petersen in press). Also in Denmark, the Vig aurochs is also an example of a single individual (Noe-Nygaard 1973); however, it is difficult to assess whether this was a whole individual intentionally deposited or an individual that escaped hunters, only to later die of exhaustion and blood loss. These sites are in clear contrast to the Star Carr assemblage, which instead of a single event, represents material from protracted and repeated occupation. Unsurprisingly, it is the larger European assemblages, from Bedburg-Königshoven and Friesack 4 and 27, that offer a closer comparison to Star Carr. The material from Bedburg-Königshoven, recovered from Early Holocene sediments in a palaeochannel in the Erft Valley within the Lower Rhine Basin, was heavily dominated by aurochs, and with the vast majority of skeletal element being present. However, this too is suggested to represent a single occupation, with whole aurochs being introduced from kill sites in the immediate area and processed, before being deposited in the palaeochannel (Street 1993). Therefore, the Star Carr assemblage, evidencing repeated occupation, including the introduction of animals as whole carcasses and as portions, the processing of meat, marrow and skins, and the deposition of faunal materials through multiple phases of activity presents a unique picture of Early Mesolithic life within North-West Europe.

One final theme that can be explored is the practice of deposition; across the North-West European sites, there appears to be a general concern for depositing animal remains in appropriate or meaningful ways. These can be broadly grouped together as practices of large-scale collation, discrete collections and the potential 'bundling' and deposition of remains. Large-scale collation can primarily be seen in the deposition of animal remains within watery context, which is documented at Friesack 4 and 27, Bedburg-Königshoven, Mönchengladbach-Geneicken and Zutphen-Ooijerhoek (Street 1993; Bos et al. 2005; Groß 2014; Heinen 2014; Schmölcke 2016) and at Star Carr.

Arguments for intentional deposition within water must be tempered by acknowledging the potential for differential preservation to only preserve the portion of a large scatter of bone that was placed within the water. However, deposition at sites such as Bedburg-Königshoven has been argued, through taphonomic analysis and spatial distributions, to represent intentional deposition in deep water (Street 1993). More specifically, large scale collation can also include acts of deposition where the remains of one or multiple phases of occupation or activity have been intentionally gathered together into a discrete deposit. This is evident in the 'midden' at Three Ways Wharf and the bone deposit at Faraday Road (Overton 2014; Chapter 11) and is also clearly present at Star Carr, within the exceptionally dense deposit of material, including faunal remains, flint, worked wood and stones in Clark's area. Here we see a clear concern for the aggregated deposition of materials, either in watery contexts, a pattern visible across many North-West European sites, or within dense collated deposits, a practice more visible within Britain.

Very similar to these, but on a smaller scale, are more discrete practices of collection; at Mönchengladbach-Geneicken, an aurochs was killed, butchered and processed for marrow, and the split long bones were returned back to the vicinity of the carcass, to create a single deposit (Heinen 2014). At Lundby Mose 1-4, Skottemarke and Favrbo in Denmark, the discrete deposits of elk remains, after processes of 
butchery and marrow extraction had been undertaken, represents a very similar process. However, these regularly contain the remains of multiple individuals and never contain whole individuals; this commingling of partial individuals appears to be a specifically Danish elaboration and has previously been argued to be strongly tied to the importance of elk in the Danish Early Mesolithic hunting strategies (Leduc 2014). Furthermore, it has been suggested that some, or all of these deposits, may have been deposited as a 'bundle, within an elk skin. These processes of deposition can also be seen in Britain, at Flixton School House Farm, where a collection of aurochs ribs, vertebrae and a single pelvis fragment were deposited in a watery hollow (Overton and Taylor forthcoming). Furthermore, these practices can also be seen at Star Carr; the lake edge contains numerous tightly grouped elements which could be intentionally collected elements deposited into water, either as piles or within skins, whilst the numerous semi-articulated limbs recovered in the detrital wood scatter also represent an intentional act of collating and depositing bodies, or in this case, portions of bodies together.

Evidence for intentional deposition, on a broad scale, highlights these processes as both widely abundant in the archaeological record, and a clear concern of hunter-gatherer groups during the Early Mesolithic. The desire to collect, collate and deposit the remains of animals and their bodies points to a shared underlying motivation to 'take care' of animal remains; however, this motivation materialises in a variety of ways, some of which are more generally visible across Europe, such as deposition in water, whilst others are more specific, such as the bundling of multiple, partial elk remains in Denmark. The treatment of animal remains, whilst guided by broader understandings and worldviews, can also be understood as developing through the specific encounters, experiences and relationships between humans and animals at particular sites and landscapes (cf Overton and Hamilakis 2013), which accounts for the specific nature of depositional acts at particular sites. At Star Carr, the dense deposit of fauna, lithics and wood may be considered as tied into broader 'middening' practice, as seen on other British sites, and the discrete collections of skeletal elements share aspects of depositions in Denmark and Germany, whilst the deposition of whole articulated portions of bodies appear to be a manifestation of depositional practices unique to Star Carr.

\section{Osseous technology}

Comparing the working of osseous materials at Star Carr with other sites in Britain is an exercise which is, to a certain extent, constrained by the character of the dataset available. Occasional finds of antlerworking debitage and osseous artefacts elsewhere in the Vale of Pickering indicate that the use of the groove-and-splinter technique (Seamer K) was not restricted to Star Carr locally, and that broken antler barbed points (Flixton Island, No Name Hill) were also deposited into other areas of wetland around Lake Flixton during the Early Mesolithic (Chapter 25). However, the scale of these activities is much smaller, with a single piece of material culture being recovered from each site to demonstrate these practices.

Further afield, there are other echoes of the Star Carr osseous repertoire within Northern England. The wetlands of Holderness, East Yorkshire, have to date produced 12 barbed points from sites such as Brandesburton, Hornsea Mere and Skipsea Withow (Clark and Godwin 1956; Davis-King 1980). Whilst these remain undated, the formal and technological similarities between these and the Star Carr assemblage are notable. In particular, the incision of short lines along the length of $<115796>$ has clear echoes within this assemblage. Landscape-level palaeoenvironmental studies have suggested that many of these artefacts were deposited into peat forming within a system of shallow lakes and meres, echoing the wetland context of Star Carr. However, there are also differences in material choices across Holderness, with bone making up eight of the 12 recovered to date, a ratio which contrasts sharply with those noted at Star Carr. Further work is needed to explore the relationship between these two landscapes fully, but at a very coarse level it appears to be another area into which bone and antler barbed points were being deposited during the Late Glacial/Early Holocene, with some formal similarities in material culture beginning to emerge.

The evidence for the working of bone and antler in Early Mesolithic Southern Britain stands in stark contrast to this. The sites noted above (Three Ways Wharf, Sanderson Site, Faraday Road and the Thatcham sites) have produced far fewer bone or antler artefacts, or osseous debitage. At sites with high levels of fragmentation (Three Ways Wharf), the apparent large quantities of long bone available for the production of bone artefacts were apparently sacrificed for marrow extraction. The small quantity of bone and antler artefacts from the Thatcham sites include an elk antler lame de hauche (Thatcham IV) and several unbarbed bone and antler 
points, the working edge of an antler axe and a possible fragment of an antler sleeve. These artefact types are not found in the Star Carr assemblage. Furthermore, the Thatcham sites have produced an assemblage of 29 pieces of red deer antler which show no signs of the groove-and-splinter process and very little sign of working generally (Elliott 2012). As such, it appears that attitudes towards working antler and bone in Southern Britain were quite distinct from those seen at Star Carr. Here, the working of red deer antler was far less intense and when it did occur, was used to produce different forms of material culture. This implies a different outlook on material culture in Southern Britain, possibly a smaller role for osseous materials in everyday life and a different set of understandings concerning the bodies and anatomy of animals. What was appropriate and important in terms of how red deer and elk carcasses were butchered and used at Star Carr does not appear to have applied to Southern Britain at this time.

The structure and organisation of the osseous technologies demonstrates an enigmatic mixture of similarities and differences with other Early Mesolithic sites across Europe. This was originally commented upon by Clark, who noted that despite the production of typologically similar forms of barbed points, the overwhelming use of red deer antler and the groove-and-splinter technique at Star Carr is unique within contemporary North-West Europe. Clark linked the use of the groove-and-splinter technique to older technical traditions observed within the Hamburgian deposits at Stellmoor and Meiendorf and more widely, across the Late Magdalenian and Azillian in France and Spain. The form of the Star Carr barbed points falls well within the range observed at the classic Maglemosian sites, as does the form of the elk antler mattocks. The aurochs bone hide-working tools are not widely seen in the Early Mesolithic of Southern Scandinavia, but similar artefacts made using elk bone are known from sites in Eastern Europe. This combination of differences and similarities, alongside the pioneering use of pollen and radiocarbon dating, led Clark to assign Star Carr a 'Proto-Maglemosian' cultural identity-an intermediary form which succeeded the Ahrensburgian and Hamburgian groups and preceded the Maglemosian in North-West Europe.

David's technological approach to the Maglemosian further refined the affinities of Star Carr to the other key Early Mesolithic sites in the region. In terms of the form of the osseous artefacts at Star Carr, there are clear typological affinities with the assemblages of Hohen Viecheln, and Phases 1 and 2 of Friesack 4 . These sites are linked through the common occurrence of worked red deer tines, aurochs bone scraping tools, elk antler mattocks and worked frontlets which are far from ubiquitous across other Early Holocene sites in Europe. The use of the groove-and-splinter technique in producing antler barbed points is also demonstrated at Hohen Viecheln (Horizon A) and Birsmatten-Basisgrotte (1955-56, Horizon 2), although in much smaller quantities than is evidenced at Star Carr. The method of producing aurochs bone scraping tools (the 'S' method) identified by David is unique to Star Carr, with the bone scraping tools of Zamostje being made from elk instead of aurochs and not utilising the dotted perforation technique in the early stages of the production sequence. David concludes that these technological and typological similarities allow Star Carr to be grouped with Early Mesolithic sites in Northern Germany. Further to this, Wild's work on the formal similarities between the Hirschgeweihkappen artefacts (see Chapter 26) from Northern Britain and Northern Germany creates a strong cultural link between Star Carr, Bedburg-Königshoven, Berlin-Biesdorf and Hohen Viecheln, which is described in terms of a cultural-evolutionary lineage (Wild 2014).

However, the analysis presented above demonstrates a substantial level of technological variability in the ways in which people worked bone and antler at Star Carr. This variation, with people finding different ways of solving technological problems when working bone and antler, and seldom following a strict set of rules throughout the production of osseous material culture, makes these comparisons harder to draw. Variations in the extent to which splinters were extracted from red deer antlers, the methods used to extract splinters, the use of scraping and filing to define barbs, and the methods used to extract marrow and create bone blanks demonstrate this apparent technical flexibility. Similarly, the typological variation apparent in the Star Carr barbed points makes it difficult to fit this assemblage into the more robust typological frameworks of Maglemosian Europe without overlooking significant portions of the dataset. Whilst the analysis presented here suggests that red deer metapodia were being split to produce blanks for barbed points, and a single bone barbed point has now been identified within the assemblage, the heavy bias towards the use of red deer antler, and the universal use of the groove-and-splinter process to produce blanks for antler barbed point manufacture, is unique within Preboreal and Maglemosian sites. This suggests a very different attitude to the use of animal materials, and the processing of animal carcasses, to similar sites from North-West Europe, despite the apparent similarities in the finished forms of osseous material culture. 
When attempting to interpret these links, the scale of analysis is important to bear in mind. On a macro-scale, the commonalities between the ways bone and antler were worked at Star Carr and other sites in Northern Germany are evident, whilst on the micro-scale, that of individual actors and technical decisions appear far less robust and much more variable. The relationship here appears much less consistent than, for instance, the Maglemosian sites which David (2005) identifies as Maglemosian stricto-sensu. So rather than a cultural consistency between these sites, it is perhaps better to suggest that the inhabitants of these places shared some common conceptual ground in terms of the forms of material culture and the techniques and traditions that can be used to work osseous materials. However, big differences still existed in the ways osseous material culture repertoires were produced, moved across landscapes and deposited. This might suggest communication, movement of people and a sharing of technological know-how around this region during the Early Mesolithic, but without the formal and repeated consistencies in material culture and technology that the term 'cultural group' has come to imply within Mesolithic studies. Ideas concerning the use of animal bodies to create material culture may have been shared between these people living around the region, but rules concerning the ways in which these should be made seem to have been more localised. 
